\title{
Dual-Retarder Mueller Polarimetry System for Extraction of Optical Properties of Serum Albumin Protein Media
}

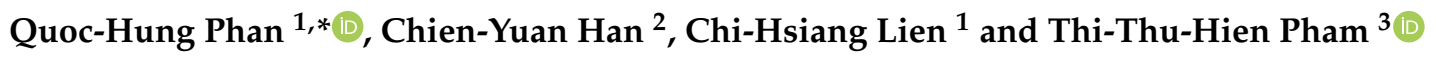 \\ 1 Department of Mechanical Engineering, National United University, Miaoli 36063, Taiwan; \\ chlien33@nuu.edu.tw \\ 2 Department of Electro-Optical Engineering, National United University, Miaoli 36063, Taiwan; \\ cyhan@gm.nuu.edu.tw \\ 3 Department of Biomedical Engineering, International University, Ho Chi Minh City 700000, Vietnam; \\ ptthien@hcmiu.edu.vn \\ * Correspondence: qhphan@nuu.edu.tw
}

Citation: Phan, Q.-H.; Han, C.-Y.;

Lien, C.-H.; Pham, T.-T.-H.

Dual-Retarder Mueller Polarimetry System for Extraction of Optical Properties of Serum Albumin Protein Media. Sensors 2021, 21, 3442. https://doi.org/10.3390/s21103442

Academic Editor: Vittorio M. N. Passaro

Received: 11 March 2021

Accepted: 13 May 2021

Published: 15 May 2021

Publisher's Note: MDPI stays neutral with regard to jurisdictional claims in published maps and institutional affiliations.

Copyright: (c) 2021 by the authors. Licensee MDPI, Basel, Switzerland. This article is an open access article distributed under the terms and conditions of the Creative Commons Attribution (CC BY) license (https:// creativecommons.org/licenses/by/ $4.0 /)$.

\begin{abstract}
A dual liquid-crystal variable retarder Mueller polarimetry system incorporating a goldbased surface plasmon resonance prism coupler was proposed for extracting the optical properties of serum albumin protein media in the reflectance configuration. The feasibility of the proposed system was demonstrated by measuring the circular dichroism and circular birefringence properties of glucose tissue phantom solutions with different albumin concentrations. The results showed that the circular dichroism increased with albumin concentration, while the optical rotation angle increased with glucose concentration. Both properties reduced over time as a result of the protein glycation effect, which led to a gradual reduction in the glucose content of the sample.
\end{abstract}

Keywords: Mueller matrix polarimetry; surface plasmon resonance; albumin; glucose concentration

\section{Introduction}

Diabetes mellitus affects an estimated 425 million people worldwide, and it is responsible for around 3.2 to 5.0 million deaths annually and a global health expenditure of approximately USD 727 billion [1]. The term "diabetes" actually covers a group of metabolic disorders characterized by high blood glucose levels over a period of time, and it is the result of the pancreas producing insufficient insulin (type 1), or the cells of the body not responding properly to the insulin produced (type 2). Effective control of the blood glucose level is essential for diabetes management, and it is most commonly performed by finger-prick testing on a daily basis. However, the invasive nature of this test is painful, costly, and there are chances of cross infection. The methods for developing noninvasive (NI) blood glucose monitoring devices have increased in recent years. Many techniques that have been proposed in the literature include optical polarimetry [2], surface plasmon resonance (SPR) [3], and Raman spectroscopy (SERS) [4]. In addition, several NI glucose monitoring devices have been commercialized, including the GlucoWatch ${ }^{\circledR}$ from Cygnus Inc., with over $94 \%$ of the readings falling within the clinically acceptable A + B region of the Clarke Error Grid [5]; the TensorTip Combo Glucometer from Cnoga Medical Ltd. with a measurement accuracy of $14.4 \mathrm{mg} / \mathrm{dL}$ [6], and the FreeStyle Libre Flash system from Abbot Inc. with an accuracy of $12-21 \mathrm{mg} / \mathrm{dL}$ [7]. However, the measurement performance of these systems is still sub-optimal as they fail to take account of the glycoxidation effect, which takes place in the presence of albumin, intralipid, and D-Glucose [8,9]. Stark et al. [10] extracted the glucose concentration in protein-containing media with a resolution of $16 \mathrm{mg} / \mathrm{dL}$. However, the albumin concentration in the measured media was limited to $1000 \mathrm{mg} / \mathrm{dL}$, which is far lower than the actual concentration of albumin in human blood plasma ( 4000 mg/dL) [11]. Thus, methods for performing glucose extraction in the presence of higher albumin concentrations and the glycoxidation effect are still required to improve the reliability of NI glucose monitoring systems. 
Mueller matrix polarimetry is a well-established technique for analyzing the anisotropic properties of turbid media, particularly biological tissues [12-14] or glucose sensing [15]. $\mathrm{Lu}$ and Chipmen [16] proposed the decomposition formalism to determine the diattenuation, retardance, and depolarization of an arbitrary Mueller matrix. Qi et al. [17] extended the Lu-Chipman decomposition Mueller matrix method for turbid media in reflection geometry. Pham et al. [18] employed the decomposition Mueller matrix for extracting effective parameters of anisotropic material. However, the Mueller matrix decomposition method required a strict sequential order of matrix components. Azzam [19] proposed a differential Mueller matrix to resolve the sequential ordering. Quijano and Diego proposed a differential Mueller matrix for characterizing the optical properties of anisotropic material [20] and for reflectance and backscattering measurements [21]. Liao and Lo [22] extracted the anisotropic parameters by using the differential Mueller matrix method. The polarimetry measurement systems generally consist of a polarization state generator (PSG) and a polarization state analyzer (PSA). Many optical components have been proposed for the construction of high-accuracy PSGs, including rotated quarter-wave plates [23], photoelastic modulators (PEM) [24], electro-optic (EO) modulators [25], and liquid crystal variable retarders (LCVRs) $[26,27]$. LCVRs are cheaper than both PEMs and EO modulators and are more accurate than rotated quarter-wave plates. Thus, many Mueller polarimetry systems based on LVCRs have been proposed in the literature. For example, Martino et al. [28] proposed a technique for optimizing the Mueller matrix extraction results by using dual LCVRs for both the PSG system and the PSA system. Boulesteix et al. [29] used a similar system to measure the Mueller matrix of stained collagen samples. Han et al. [30] proposed a rapid full Mueller imaging polarimetry system based on LCVRs for extracting the Mueller matrix of shrimp shells under heating treatment. In previous studies [31,32], the present group proposed an enhanced Mueller polarimetry system for NI glucose concentration measurement incorporating two EO modulators and a SPR prism coupler. However, the proposed system is expensive and requires a complicated calibration of the EO components. Furthermore, the feasibility of the proposed system was evaluated using only pure tissue phantom solutions without albumin. Accordingly, the present study proposed a cheaper Mueller polarimetry system based on dual LVCRs for the extraction of the glucose concentration in samples containing albumin with a concentration as high as $1000-3000 \mathrm{mg} / \mathrm{dL}$.

\section{Differential Mueller Matrix Formalism for Extracting Circular Birefringence/Circular Dichroism (CB/CD) Properties}

Figure 1 presents a schematic illustration of the SPR prism coupler incorporated within the proposed Mueller polarimetry system. As shown, the coupler has the form of a B270 glass half-ball lens (Thorlabs ACL1210U) with a Cr-Au thin film layer (thickness $d_{1}=20 \mathrm{~nm}$ ) and $\mathrm{Ta}_{2} \mathrm{O}_{5}$ thin film layer (thickness $d_{2}=12 \mathrm{~nm}$ ) coated on its lower surface. The lens and $\mathrm{Cr}-\mathrm{Au}$ layer have refractive indices of 1.52 and 0.36-2.9 $\mathrm{i}$, respectively, while the $\mathrm{Ta}_{2} \mathrm{O}_{5}$ film has refractive indices of 1.637, 1.449, and 1.589 at a wavelength of $633 \mathrm{~nm}$ [33]. As shown in the top-left corner of the figure, the resonance angle of the coupler is equal to $60^{\circ}$ at a wavelength of $632.8 \mathrm{~nm}$ and results in a reflectance coefficient $R_{p p} \leq 0.1$.

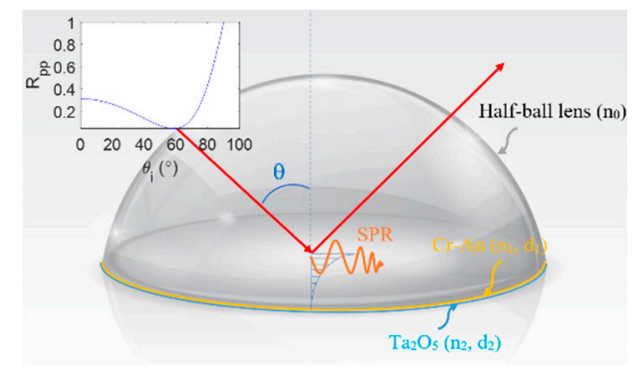

Figure 1. Schematic illustration of SPR prism coupler. 
The albumin-containing sample can be described as $S=M \times S^{\prime}$, where $\mathrm{M}$ is the Mueller matrix of the sample, and $S^{\prime}$ and $S$ are the Stokes vector of the input light and output light, respectively. The use of four polarization input lights, namely $0^{\circ}, 45^{\circ}, 90^{\circ}$, and one right-hand input light, yields a sufficient number of equations to determine the Mueller matrix of sensor $M$. The Stokes vectors of those input lights are given as follows: $S_{0^{\circ}}^{\prime}=\left[\begin{array}{llll}1 & 1 & 0 & 0\end{array}\right]^{T}, S_{45^{\circ}}^{\prime}=\left[\begin{array}{llll}1 & 0 & 1 & 0\end{array}{ }^{T}, S_{90^{\circ}}^{\prime}=\left[\begin{array}{llll}1 & -1 & 0 & 0\end{array}\right]^{T}\right.$, and $S_{R}^{\prime}=\left[\begin{array}{llll}1 & 0 & 0 & 1\end{array}\right]^{T}$. The Mueller matrix of the albumin-containing sample is then given by

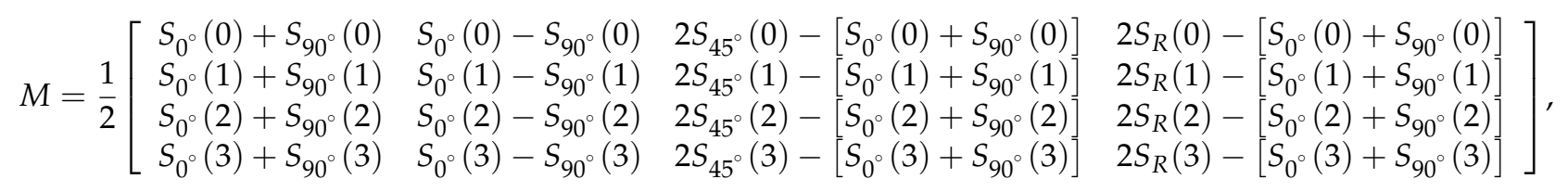

where $S_{0^{\circ}}, S_{45^{\circ}}, S_{90^{\circ}}$, and $S_{R}$ are the output Stokes parameters corresponding to input lights with $0^{\circ}, 45^{\circ}, 90^{\circ}$, and right-hand circular polarization states, respectively. The differential Mueller matrix of albumin-containing samples is obtained as [32]

$$
m=v \times\left(\frac{\ln (\lambda)}{z}\right) \times v^{-1}=\left[\begin{array}{llll}
m_{11} & m_{12} & m_{13} & m_{14} \\
m_{21} & m_{22} & m_{23} & m_{24} \\
m_{31} & m_{32} & m_{33} & m_{34} \\
m_{41} & m_{42} & m_{43} & m_{44}
\end{array}\right]
$$

where $v$ and $\lambda$ are the eigenvalues and eigenvectors of the Mueller matrix, $M$, respectively, and $\mathrm{z}$ is the axis of the coordinate system. When performing the differential Mueller matrix calculation in reflectance mode, the strong backscattering yields negative eigenvalues of the Mueller matrix, making it unphysical, and this primarily arises due to the contribution of the helicity-flipped backscattered light [32]. Nonetheless, the differential calculation can still be applied for weak scattering media in the reflectance configuration [25] or an extended differential Mueller matrix, which takes into account the sign convention [21]. In this study, the SPR prism coupler was employed to create totally internal reflectance, thus minimizing scattering. Notably, the SPR prism coupler also enhanced the performance of the detection results.

The differential Mueller matrix of an albumin-containing sample with $\mathrm{CB} / \mathrm{CD}$ properties can be expressed as $[22,34]$

$$
m^{\prime}=\frac{1}{d}\left[\begin{array}{cccc}
\ln \left[\left(1-R^{2}\right)\right] & 0 & 0 & \ln \left(\frac{1+R}{1-R}\right)+\kappa_{v}^{\prime} \\
0 & \ln \left[\left(1-R^{2}\right)\right]-\kappa_{i q}^{\prime} & 2 \gamma+\eta_{v}^{\prime} & 0 \\
0 & -2 \gamma+\eta_{v}^{\prime} & \ln \left[\left(1-R^{2}\right)\right]-\kappa_{i u}^{\prime} & 0 \\
\ln \left(\frac{1+R}{1-R}\right)-\kappa_{v}^{\prime} & 0 & 0 & \ln \left[\left(1-R^{2}\right)\right]-\kappa_{i v}^{\prime}
\end{array}\right]
$$

where $d$ is the sample thickness, $\kappa_{i q, i u, i v}^{\prime}$ is the diagonal depolarization, $\kappa_{v}^{\prime}$ is the anomalous dichroism, $\gamma$ is the optical rotation angle of $\mathrm{CB}$, and $R$ is the $\mathrm{CD}$ properties. By equating Equations (2) and (3), the optical rotation angle $\gamma$ and circular dichroism $R$ can be obtained respectively as [22]

$$
\begin{gathered}
\gamma=\frac{m_{23}-m_{32}}{4}, 0 \leq \gamma \leq 180^{\circ} \\
R=\frac{\exp \left(\frac{m_{14}+m_{41}}{2}\right)-1}{\exp \left(\frac{m_{14}+m_{41}}{2}\right)+1}
\end{gathered}
$$
as [35]

Finally, the glucose concentration of the albumin-containing samples can be obtained

$$
C=\frac{\gamma}{[\gamma]_{\lambda} l}
$$


where $[\gamma]_{633}=45.23 \mathrm{deg} /(\mathrm{dm} \mathrm{g} / \mathrm{mL})$ is the unique specific rotation angle of a particular molecule, and $l$ is the path length and is equal to the double active layer thickness of the SPR sensor. CB is the difference in refraction of the right and left circularly polarized lights. The optical rotation angle $\gamma$ describes the rotation of the plane of polarized light traversing a CB medium (albumin-containing glucose sample). The different glucose concentrations are associated with different optical rotation angles. As shown in Equation (6), the optical rotation angle $\gamma$ increases linearly with the glucose concentration C. Furthermore, the circular dichroism $\mathrm{R}$ describes the difference in absorption of the right and left circular polarization lights caused by the difference in concentration of albumin protein. Thus, extracting $\gamma$ and $R$ enables the detection of glucose and albumin concentration in human blood plasma.

\section{Experimental Setup and Results}

Figure 2 presents a schematic illustration of the proposed dual-retarder Mueller polarimetry system consisting mainly of a PSG and a commercial Stokes polarimeter (PAX1000VIS, Thorlabs Inc., Newton, NJ, USA) with an accuracy of $\pm 25^{\circ}$. As shown, the PSG comprises a He-Ne laser (633 nm, 1135P, Lumentum Operations LLC, San Jose, CA, USA), a polarizer (GTH5M, Thorlabs Inc.) with the principal angle adjusted to $45^{\circ}$, and two LCVRs (LCC2415VIS/M, Thorlabs Inc.) with slow axis angles of $90^{\circ}$ and $45^{\circ}$. The Stokes vectors of the light passing from the PSG are obtained as

$$
S=\operatorname{LCVR}\left(\delta_{2}, 45^{\circ}\right) \operatorname{LCVR}\left(\delta_{1}, 90^{\circ}\right) S_{i n}^{\prime}
$$

Thus,

$$
\left[\begin{array}{c}
1 \\
-\sin \delta_{1} \sin \delta_{2} \\
\cos \delta_{1} \\
\cos \delta_{2} \sin \delta_{1}
\end{array}\right]=\left[\begin{array}{cccc}
1 & 0 & 0 & 0 \\
0 & \cos \delta_{2} & 0 & -\sin \delta_{2} \\
0 & 0 & 1 & 0 \\
0 & \sin \delta_{2} & 0 & \cos \delta_{2}
\end{array}\right]\left[\begin{array}{cccc}
1 & 0 & 0 & 0 \\
0 & 1 & 0 & 0 \\
0 & 0 & \cos \delta_{1} & -\sin \delta_{1} \\
0 & 0 & \sin \delta_{1} & \cos \delta_{2}
\end{array}\right]\left[\begin{array}{l}
1 \\
0 \\
1 \\
0
\end{array}\right]
$$

where $\delta_{1}$ and $\delta_{2}$ are the adjustable phase retardations of the two LCVRs, respectively. The output polarization states of light generated by the PSG by setting a differential set of values of $\delta_{1}$ and $\delta_{2}$ are shown in Table 1 . When performing the calibration, the first LCVR was adjusted to the principal angle of $90^{\circ}$. The output light will be vertical and $45^{\circ}$ at the phase retardation angles of $90^{\circ}$, and $0^{\circ}$, respectively. The second LCVR was adjusted to the principal angle of $45^{\circ}$, and the phase retardances of the two LCVRs were set as Table 1 to generate three linear polarization lights $\left(0^{\circ}, 45^{\circ}\right.$, and $\left.90^{\circ}\right)$ and one circular polarization light (right-hand). We should note that the calibration process for the LCVR system is much easier than that of the EO system proposed in [31,32]. Furthermore, the time taken for one circle of scanning was set equal to $3 \mathrm{~s}$, and the measured results of the Mueller matrix of air, the half-wave plate, and mirror are shown in Table 2. As shown, the elements of the air matrix had a maximum error of just $10^{-3}$, and for the half-wave plate and mirror, the matrix elements had a maximum error of $10^{-2}$, comparable with the accuracy and speed of the EO system proposed in [31,32]. Notably, the cost of the LCVR system is four times lower than that of the EO system. 


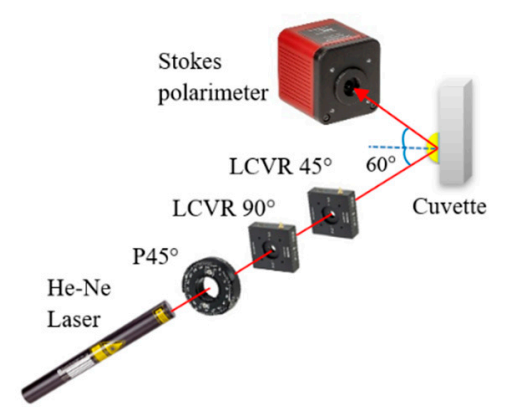

Figure 2. Schematic illustration of dual-retarder Mueller polarimetry system.

Table 1. Output polarization states generated by dual-retarder Muller polarimetry system.

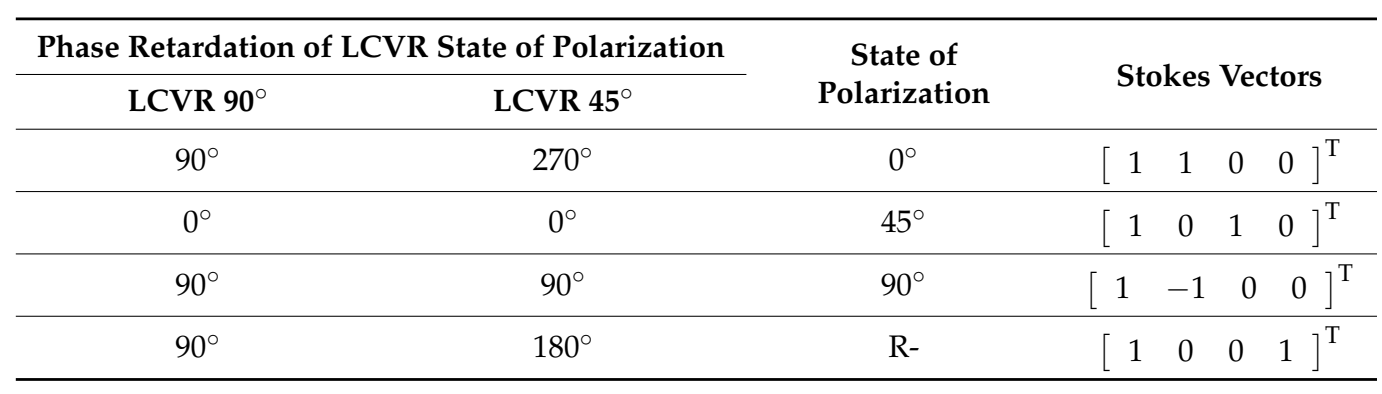

Table 2. Measured Mueller matrices of standard optical samples.

\begin{tabular}{cccc}
\hline \multicolumn{1}{c}{ Air } & Half-Wave Plate & \multicolumn{1}{c}{ Mirror } \\
\hline$\left[\begin{array}{ccccccc}1 & 0 & 0 & 0 \\
0 & 1 & 0 & -0.0010 \\
-0.0055 & -0.0045 & 1 & 0.0055 \\
0 & 0 & -0.0010 & 0.9998\end{array}\right]\left[\begin{array}{cccccc}1 & 0 & 0 & 0 \\
0 & 1 & -0.0200 & 0 \\
0.0200 & 0 & -0.9900 & 0.0173 \\
0.0009 & -0.0209 & -0.0409 & -1\end{array}\right]\left[\begin{array}{cccc}1 & 0 & 0 \\
0 & 1 & -0.0400 & 0.0100 \\
0 & -0.0300 & -1 & 0.0150 \\
0 & 0.0100 & 0.0736 & -1\end{array}\right]$ \\
\hline
\end{tabular}

When performing the experiments, the incident angle of the laser light was set equal to $60^{\circ}$. It should be noted that this is the SPR prism coupler resonance angle. In addition, the sample solution was stored in quartz cuvettes with dimensions of $10 \times 10 \times 1 \mathrm{~mm}^{3}$. Before attaching the coupler to the cuvettes, a small $6 \mathrm{~mm}$-diameter hole was drilled on the cuvettes to secure that sample's contact directly with the half-ball lens flat surface. Thus, the effect of the cuvette's material to the measurement results can be neglected.

\subsection{Albumin Protein Detection in Glucose Tissue Phantom Solution with $2 \%$ Lipofundin}

The preparation method of samples is described in detail in [32]. In brief, deionized water (DI), D-glucose (Merck Ltd., Darmstadt, Germany), and 2\% lipofundin (lipofundin $\mathrm{MCT} / \mathrm{LC1} 20 \%$, B | Braun) were mixed with an appropriate ratio. The concentrations of the glucose sample were $0 \sim 500 \mathrm{mg} / \mathrm{dL}$ in $100 \mathrm{mg} / \mathrm{dL}$ increments. Additional glucose tissue phantom samples with concentrations of 60 and $80 \mathrm{mg} / \mathrm{dL}$ were also prepared to simulate a small glucose concentration situation. The samples were mixed with three different bovine serum albumin (Sigma Aldrich, Darmstadt, Germany) concentrations, namely 1000, 2000, and $3000 \mathrm{mg} / \mathrm{dL}$. Figure 3 shows the experimental results obtained for the circular dichroism $(R)$ properties of the various samples. As shown in Figure 3a, the circular dichroism remained unchanged as the glucose concentration increased for all three values of the albumin concentration. However, for a constant glucose concentration, the $R$ value increased from 0.01 to 0.03 as the albumin concentration increased from 1000 to $3000 \mathrm{mg} / \mathrm{dL}$. Figure $3 \mathrm{~b}$ confirms that for all values of the glucose concentration, the circular dichroism increased linearly with albumin concentration. The average standard deviation of the measured values of $R$ over four repeated tests was found to be $1.6 \times 10^{-2}$. 


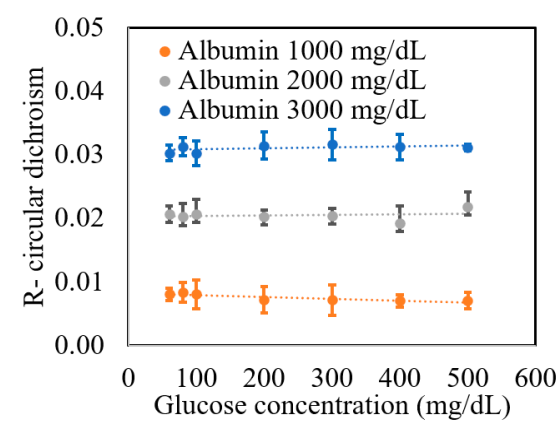

(a)

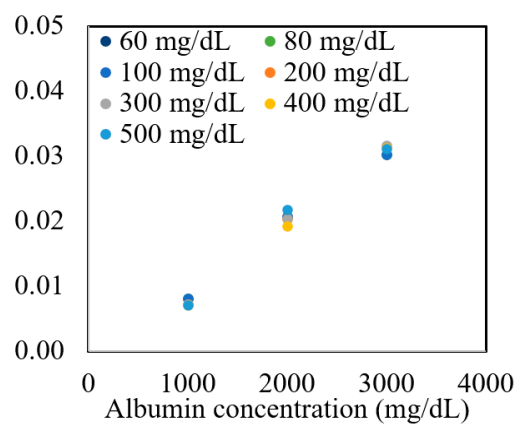

(b)

Figure 3. Experimental results for variation in $R$ with: (a) glucose concentration as a function of albumin concentration, and (b) albumin concentration as a function of glucose concentration.

A further series of experiments was performed to investigate the protein glycation effect of albumin by measuring the variation in the optical rotation angle and circular dichroism of glucose tissue phantom solutions with concentrations of 100,300 , and $500 \mathrm{mg} / \mathrm{dL}$, respectively, over a period of six hours. Each sample was mixed with three different albumin concentrations, namely 1000, 2000, and $3000 \mathrm{mg} / \mathrm{dL}$. The corresponding results are presented in Figures 4-6, respectively. For all three albumin concentrations, the optical rotation angle of the glucose samples decreased rapidly over the first two hours and then continued to decrease more slowly over the remaining four hours. The $\mathrm{CD}$ also reduced continuously over the considered time period. Furthermore, the sample with $2000 \mathrm{mg} / \mathrm{dL}$ of albumin showed a higher reduction in CD than the samples with 1000 and $3000 \mathrm{mg} / \mathrm{dL}$ of albumin. It is suspected that for glucose concentrations over the range of 0-500 mg/dL, the protein glycation rate is highest at an albumin concentration of $2000 \mathrm{mg} / \mathrm{dL}$. Overall, the results confirmed that in the presence of albumin, protein glycation occurs, which results in a lowering of the sugar content in the solution [8], as well as reductions in the extracted values of the optical rotation angle and circular dichroism accordingly. The average standard deviations of the extracted values of $\gamma$ and $R$ over four repeated tests were determined to be $7.9 \times 10^{-2 \circ}$ and $2.4 \times 10^{-3}$, respectively.

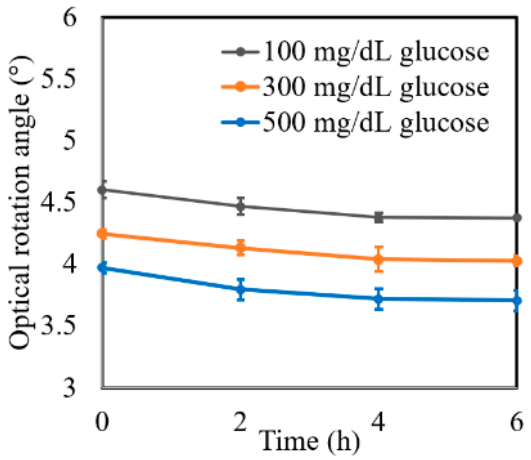

(a)

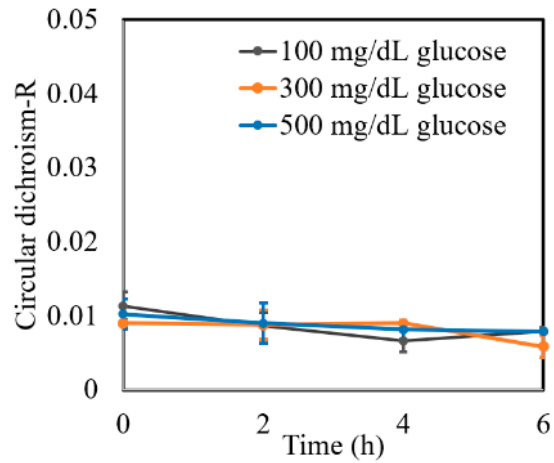

(b)

Figure 4. Experimental results for variation in: (a) $\gamma$ and (b) $R$ of glucose tissue phantom solutions mixed with $1000 \mathrm{mg} / \mathrm{dL}$ of albumin over time interval of $6 \mathrm{~h}$. 


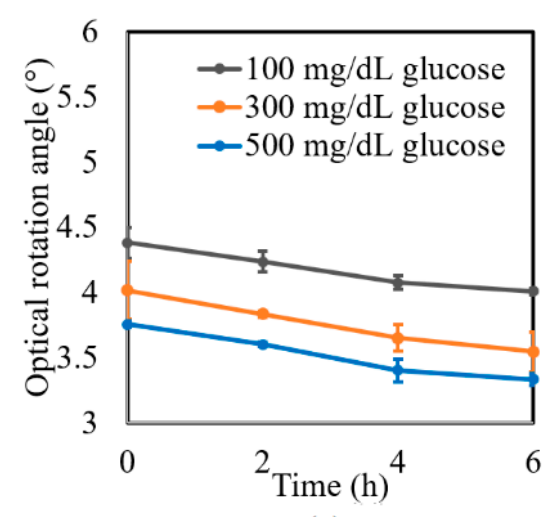

(a)

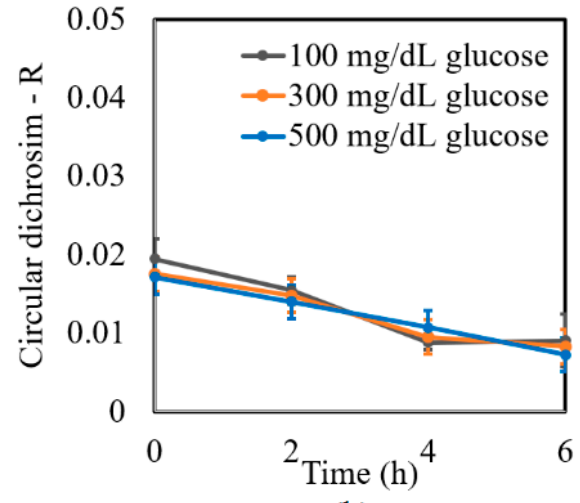

(b)

Figure 5. Experimental results for variation in: (a) $\gamma$ and (b) $R$ of glucose tissue phantom solutions mixed with $2000 \mathrm{mg} / \mathrm{dL}$ of albumin over time interval of $6 \mathrm{~h}$.

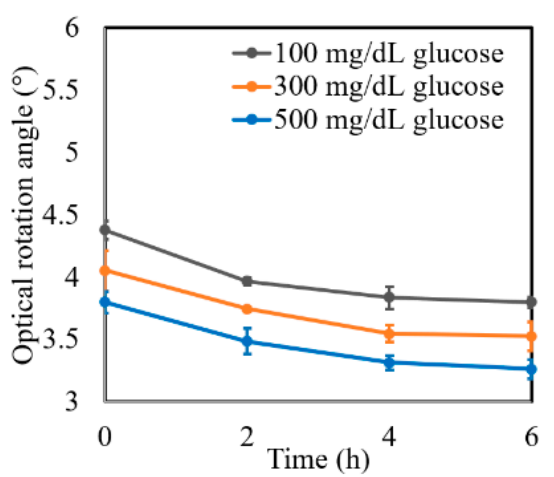

(a)

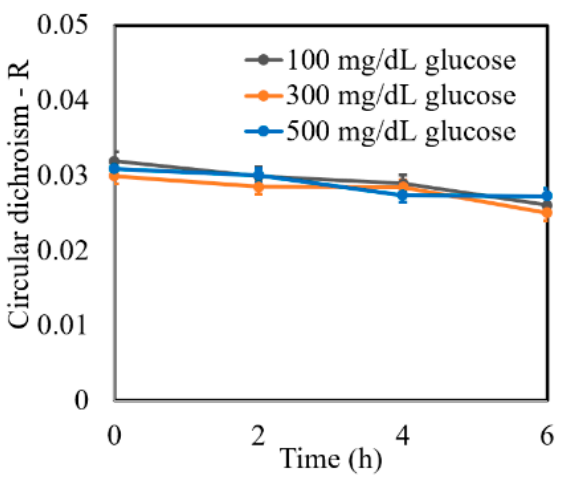

(b)

Figure 6. Experimental results for variation in: (a) $\gamma$ and (b) $R$ of glucose tissue phantom solutions mixed with $3000 \mathrm{mg} / \mathrm{dL}$ of albumin over time interval of $6 \mathrm{~h}$.

\subsection{Glucose Concentration Detection in Albumin-Containing Media}

Figure 7a shows the experimental results obtained for the variation in $\gamma$ of the tissue phantom solutions with the glucose concentration given the addition of albumin in concentrations of $0,1000,2000$, and $3000 \mathrm{mg} / \mathrm{dL}$. For each of the albumin concentrations, $\gamma$ increased linearly with glucose concentration over the considered measurement range. However, for a constant glucose concentration, $\gamma$ decreased with albumin concentration due to the glycoxidation effect. The standard deviation of the measured values of $\gamma$ over four repeated tests was found to be $5.2 \times 10^{-2}$.

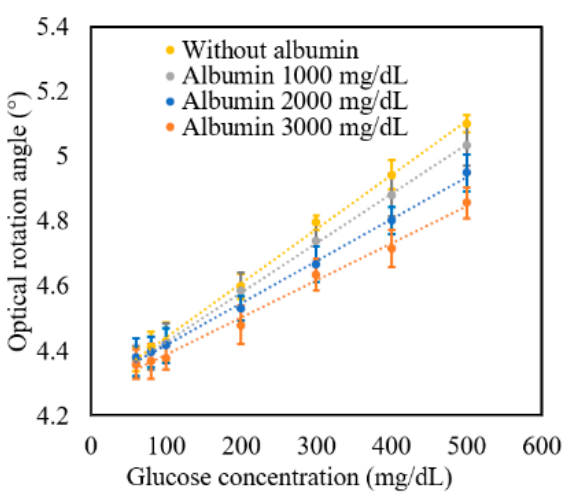

(a)

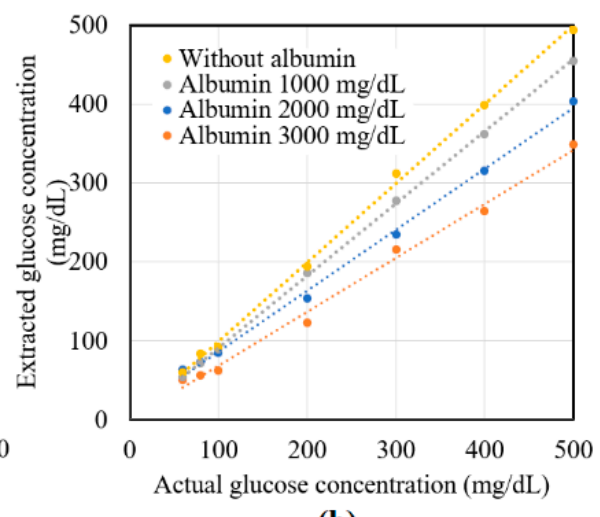

(b)

Figure 7. Experimental results for variation in: (a) $\gamma$ and (b) $R$ of glucose tissue phantom solutions mixed with $3000 \mathrm{mg} / \mathrm{dL}$ of albumin over time interval of $6 \mathrm{~h}$. 
Figure $7 \mathrm{~b}$ compares the extracted glucose concentrations obtained from Equation (6) with the known glucose concentrations of the various samples. Table 3 shows the extracted values of the glucose concentrations for the samples with no albumin addition. As shown, the maximum extraction error was $9.36 \%$ for the sample with a glucose concentration of $100 \mathrm{mg} / \mathrm{dL}$. Moreover, the average error value and percentage were equal to $5.74 \mathrm{mg} / \mathrm{dL}$ and $3.34 \%$, respectively. The accuracy of the extraction results was thus in good agreement with the value of $10 \mathrm{mg} / \mathrm{dL}$ reported in a previous study [32]. Table 4 shows the extraction results obtained for the glucose samples with different albumin concentrations. As described earlier, the glucose concentration reduced with albumin concentration due to the protein glycoxidation effect. Moreover, the extent of the reduction in the sugar level increased with glucose concentration. The protein glycation rate was faster with the higher albumin concentration. In the future, the high protein glycation samples consisting of both albumin (with actual concentration in human blood plasma-4000 mg/dL) and globulin proteins will be studied. Furthermore, a clinical study will be performed on volunteers including patients with diabetes to confirm the practical feasibility of the proposed technique for NI glucose sensing.

Table 3. Extraction errors for glucose concentration of tissue phantom solutions without albumin.

\begin{tabular}{cccccccc}
\hline Actual glucose concentration $(\mathrm{mg} / \mathrm{dL})$ & 60 & 80 & 100 & 200 & 300 & 400 & 500 \\
\hline Extracted glucose concentration $(\mathrm{mg} / \mathrm{dL})$ & 58 & 82 & 91 & 193 & 311 & 398 & 492 \\
\hline Error value $(\mathrm{mg} / \mathrm{dL})$ & 2 & 2 & 9 & 7 & 11 & 2 \\
\hline Error percentage & $2.78 \%$ & $2.19 \%$ & $9.36 \%$ & $3.44 \%$ & $3.51 \%$ & $0.59 \%$ & $1.53 \%$ \\
\hline
\end{tabular}

Table 4. Extraction values of glucose concentration for tissue phantom solutions with different albumin concentrations.

\begin{tabular}{cccccccccc}
\hline Actual glucose concentration $(\mathrm{mg} / \mathrm{dL})$ & & 60 & 80 & 100 & 200 & 300 & 400 & 500 \\
\hline \multirow{3}{*}{ Extracted glucose concentration with albumin } & $1000 \mathrm{mg} / \mathrm{dL}$ & 52 & 70 & 88 & 184 & 276 & 361 & 453 \\
\cline { 2 - 7 } & $2000 \mathrm{mg} / \mathrm{dL}$ & 62 & 72 & 84 & 152 & 233 & 314 & 402 \\
\cline { 2 - 8 } & $3000 \mathrm{mg} / \mathrm{dL}$ & 49 & 55 & 61 & 122 & 214 & 262 & 347 \\
\hline
\end{tabular}

\section{Conclusions}

This study presented an enhanced CD/CB measurement technique based on a dualretarder Mueller matrix polarimetry system and a gold-based SPR prism coupler in the reflectance configuration. The validity of the proposed method was demonstrated by measuring the circular dichroism $(R)$ and optical rotation angle $(\gamma)$ of glucose tissue phantom solutions with different glucose and albumin concentrations. The results showed that the circular dichroism increased with both the glucose concentration and albumin concentration. The standard deviation of the measured circular dichroism over four repeated tests was shown to be approximately $1.6 \times 10^{-2}$. It was additionally shown that the optical rotation angle increased linearly with the glucose concentration. Notably, the results showed that the proposed technique was able to detect the reduction in the glucose concentration caused by protein glycation. The feasibility of the proposed system was demonstrated by comparing the extracted values of the glucose concentration with the known glucose concentrations of the corresponding samples. The results showed that the proposed technique was able to detect glucose with an average error of $5.74 \mathrm{mg} / \mathrm{dL}$ over the glucose concentration range of $60 \sim 500 \mathrm{mg} / \mathrm{dL}$. Overall, the results confirmed that the proposed technique provides a promising tool for detecting the glucose concentration in real-world biological samples containing albumin, intralipid, and D-Glucose.

Author Contributions: Conceptualization and methodology, Q.-H.P. and C.-Y.H.; software, validation, formal analysis, C.-Y.H.; investigation, resources, data curation, Q.-H.P. and T.-T.-H.P.; writing-original draft preparation, Q.-H.P.; writing—review and editing, Q.-H.P. and C.-H.L.; visu- 
alization, supervision, project administration, funding acquisition, Q.-H.P. All authors have read and agreed to the published version of the manuscript.

Funding: This research was funded by Ministry of Science and Technology of Taiwan, grant number "108-2218-E-239-002-MY2".

Institutional Review Board Statement: Not applicable.

Informed Consent Statement: Not applicable.

Data Availability Statement: Data available on request.

Acknowledgments: The authors gratefully acknowledge the financial support provided to this study by the Ministry of Science and Technology of Taiwan (MOST) under Grant No. 108-2218-E-239-002MY2. The authors thank Yu-Lung Lo from the Mechanical Engineering Department of National Cheng Kung University, for sharing laboratory equipment.

Conflicts of Interest: The authors declare no conflict of interest.

\section{References}

1. Guariguata, L.; Whiting, D.R.; Weil, C.; Unwin, N. The international diabetes federation diabetes atlas methodology for estimating global and national prevalence of diabetes in adults. Diab. Res. Clin. Pract. 2011, 94, 322-332. [CrossRef]

2. Cameron, B.D.; Coté, G.L. Noninvasive glucose sensing utilizing a digital closed-loop polarimetric approach. IEEE Trans. Biomed. Eng. 1997, 44, 1221-1227. [CrossRef]

3. Kumar, L.; Gupta, R.; Thakar, D.; Vibhu, V.; Annapoorni, S. A new route to glucose sensing based on surface plasmon resonance using polyindole. Plasmonics 2013, 8, 487-494. [CrossRef]

4. Neilsen, S.M.L.; Pors, A.; Banke, S.O.; Henriksen, J.E.; Hepp, D.K.; Weber, A. Critical depth Raman spectroscopy enables home use noninvasive glucose monitoring. PLOS ONE 2018, 13, 0197134.

5. Tierney, M.J.; Tamada, T.A.; Potts, R.O.; Jovanovic, L.; Garf, S.; Cygnus Research Team. Clinical evaluation of the GlucoWatch ${ }^{\circledR}$ biographer: A contrinual noninvasive glucose monitor for patients with diabetes. Biosens. Bioelectron. 2001, 16, 621-629. [CrossRef]

6. Pfutzner, A.; Strobl, S.; Demircik, A.; Redert, L.; Pfutzner, J.; Pfutzner, A.; Lier, A. Evaluation of a new noninvasive glucose monitoring device by means of standardized meal experiments. J. Diabetes. Sci. Technol. 2018, 12, 1178-1183. [CrossRef]

7. Fokkert, M.J.; Dijk, P.R.; Edens, M.A.; Abbes, S.; Jong, D.; Slingerland, R.J.; Bilo, H.J.G. Performance of the Freestyle Libre Flash glucose monitoring system in patients with type 1 and 2 diabetes mellitus. BMJ Open. Diabetes. Res. Care. 2018, 5, 000320. [CrossRef]

8. Sadowska-Bartosz, I.; Galiniak, S.; Bartosz, G. Kinetics of glycoxidation of bovine serum albumin by glucose, fructose and ribose and its prevention by food components. Molecules 2014, 19, 18828-18849. [CrossRef]

9. Bartosz, I.S.; Galiniak, S.; Batosz, G. Kinetics of glycoxidation of bovine serum albumin by methylglyoxal and glyoxal and its prevention by various compunds. Molecules 2014, 19, 4880-4896. [CrossRef]

10. Stark, C.; Arrieta, C.A.C.; Behoozian, R.; Redmer, B.; Fiedler, F.; Muller, S. Broadband polarimetric glucose determination in protein containing media using characteristic optical rotatory dispersion. Biomed. Opt. Express 2019, 10, 6340-6350. [CrossRef]

11. Hazen, K.H.; Arnold, M.A.; Small, G.W. Measurement of glucose and other analytes in undiluted human serum with nearinfrared transmission spectroscopy. Anal. Chim. Acta 1998, 371, 255-267. [CrossRef]

12. Devlaminck, V.; Ossikovski, R. Uniquenes of the differential Mueller matrix of uniform homogenous media. Opt. Lett. 2019, 39, 3149-3152. [CrossRef]

13. He, H.; Zeng, N.; Li, D.; Liao, R.; Ma, H. Quantitative Mueller matrix polarimetry techniques for biological tissues. J. Innov. Opt. Health Sci. 2012, 5, 1250017. [CrossRef]

14. Swami, M.K.; Manhas, S.; Patel, H.; Gupta, P.K. Mueller matrix measurement on absorbing turbid media. Appl. Opt. 2010, 49, 3458-3464. [CrossRef] [PubMed]

15. Phan, Q.H.; Lo, Y.L. Stokes-Mueller matrix polarimetry system for glucose sensing. Opt. Laser. Eng. 2017, 92, 120-128. [CrossRef]

16. Lu, S.Y.; Chipman, R.A. Interpretation of Mueller matrices based on polar decomposition. J. Opt. Soc. Am. A 1996, 13, 1106-1113. [CrossRef]

17. Qi, J.; He, H.H.; Ma, H.; Elson, D.S. Extended polar decomposition method of Mueller matrices for turbid media in reflection geometry. Opt. Lett. 2017, 42, 4048-4051. [CrossRef] [PubMed]

18. Pham, T.H.H.; Nguyen, A.L.T.; Vo, T.V.; Huynh, K.C.; Phan, Q.H. Optical parameters of human blood plasma, collagen, and calfskin based on the Stokes Mueller technique. Appl. Opt. 2018, 57, 4353-4358. [CrossRef]

19. Azzam, R.M. Propagation of partially polarized light through anisotropic media with or without depolarization: A differential $4 \times 4$ matrix calculus. J. Opt. Soc. Am. 1978, 68, 1756-1767. [CrossRef]

20. Quijano, N.O.; Diego, J.L.A. Mueller matrix differential decomposition. Opt. Lett. 2011, 36, 1942-1944. [CrossRef]

21. Quijano, N.O.; Diego, J.L.A. Mueller matrix differential decomposition for direction reversal: Application to samples measures in reflection and backscattering. Opt. Express 2011, 19, 14348-14353. [CrossRef] 
22. Liao, C.C.; Lo, Y.L. Extraction of anisotropic parameters of turbid media using hybrid model comprising differential and decomposition-based Mueller matrices. Opt. Express 2013, 21, 16831-16853. [CrossRef]

23. Azzam, R.M.A. Stokes vector and Muller matrix polarimetry. J. Opt. Soc. Am. A 2016, 33, 1396-1408. [CrossRef]

24. Arteaga, O.; Freudenthal, J.; Wang, B.L.; Kahr, B. Mueller matrix polarimetry with four photoelastic modulators: Theory and calibration. Appl. Opt. 2012, 51, 6805-6817. [CrossRef]

25. Phan, Q.H.; Lo, Y.L. Differential Mueller matrix polarimetry technique for noninvasive measurement of glucose concentration on human fingertip. Opt. Express 2017, 25, 15179-15187. [CrossRef] [PubMed]

26. Han, C.Y.; Du, C.Y.; Chen, D.F. Evaluation of structural and molecular variation of starch granules during the gelatinization process by using the rapid Mueller matrix imaging polarimetry system. Opt. Express 2018, 26, 15851-15866. [CrossRef]

27. Parejo, P.G.; Jara, A.C.; Caurel, E.G.; Arteaga, O.; Herrero, A.A. Nonideal optical response of liquid crystal variable retarder and its impact on their performance as polarization modulators. J. Vac. Sci. Technol. B 2020, 38, 014009. [CrossRef]

28. Martino, A.D.; Kim, Y.K.; Caurel, E.G.; Laude, B.; Drevillon, D. Optimized Mueller polarimeter with liquid crystal. Opt. Lett. 2003, 28, 616-618. [CrossRef] [PubMed]

29. Boulesteix, B.L.; Martino, A.D.; Drevillon, B.; Schwartz, L. Mueller polarimetric imaging system with liquid crystal. Appl. Opt. 2004, 43, 2824-2832. [CrossRef]

30. Han, C.Y.; Du, C.Y.; Jhou, J.Y. Rapid full Mueller matrix imaging polarimetry based on the hybrid phase modulation technique. Opt. Commun. 2017, 382, 501-508. [CrossRef]

31. Phan, Q.H.; Lai, Y.R.; Xiao, W.Z.; Pham, T.T.H.; Lien, C.H. Surface plasmon resonance prism coupler for enhanced circular birefringence sensing and application to noninvasive glucose detection. Opt. Express 2020, 28, 24889-24899. [CrossRef]

32. Phan, Q.H.; Jian, T.H.; Huang, Y.U.; Lai, Y.R.; Xiao, W.Z.; Chen, S.W. Combination of surface plasmon esonance and differential Mueller matrix formalism for noninvasive glucose sensing. Opt. Laser. Eng. 2020, 134, 106268. [CrossRef]

33. Lin, F.; Jen, Y.J. Use of $\mathrm{Ta}_{2} \mathrm{O}_{5}$ biaxial thin films as a high efficiency polarization converter. J. Nanophotonics $2012,6,061507$. [CrossRef]

34. Ossikovski, R. Differential matrix formalism for depolarizing anisotropic media. Opt. Lett. 2011, 36, 2330-2332. [CrossRef]

35. Ansari, R.R.; Bokle, S.; Rovati, L. New optical scheme for a polarimetric based glucose sensor. J. Biomed. Opt. 2004, 9, 103-115. [CrossRef] [PubMed] 